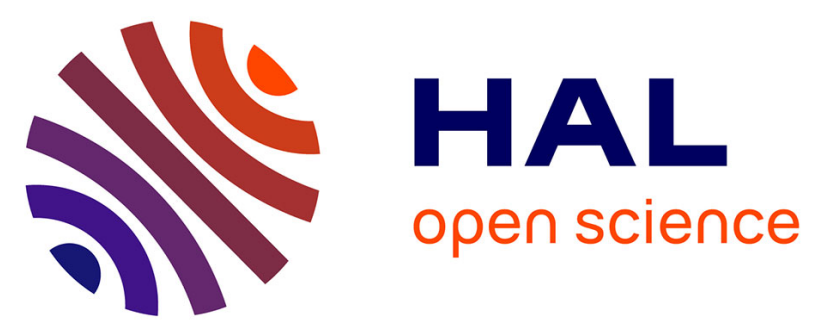

\title{
Design and Implementation of Crop Recommendation Fertilization Decision System Based on WEBGIS at Village Scale
}

Hao Zhang, Li Zhang, Yanna Ren, Juan Zhang, Xin Xu, Xinming Ma, Zhongmin $\mathrm{Lu}$

\section{To cite this version:}

Hao Zhang, Li Zhang, Yanna Ren, Juan Zhang, Xin Xu, et al.. Design and Implementation of Crop Recommendation Fertilization Decision System Based on WEBGIS at Village Scale. 4th Conference on Computer and Computing Technologies in Agriculture (CCTA), Oct 2010, Nanchang, China. pp.357364, 10.1007/978-3-642-18336-2_44. hal-01562771

\section{HAL Id: hal-01562771 \\ https://hal.inria.fr/hal-01562771}

Submitted on 17 Jul 2017

HAL is a multi-disciplinary open access archive for the deposit and dissemination of scientific research documents, whether they are published or not. The documents may come from teaching and research institutions in France or abroad, or from public or private research centers.
L'archive ouverte pluridisciplinaire HAL, est destinée au dépôt et à la diffusion de documents scientifiques de niveau recherche, publiés ou non, émanant des établissements d'enseignement et de recherche français ou étrangers, des laboratoires publics ou privés. 


\title{
Design and Implementation of Crop Recommendation Fertilization Decision System Based on WEBGIS at Village Scale
}

\author{
Hao Zhang ${ }^{1}$, Li Zhang ${ }^{1}$, Yanna Ren ${ }^{1}$, Juan Zhang ${ }^{1}$, Xin Xu ${ }^{1}$,Xinming Ma ${ }^{1,2^{*}}$, \\ Zhongmin $\mathrm{Lu}^{3}$ \\ ${ }^{1}$ College of Information and Management Science, Henan Agricultural University, \\ Zhengzhou 450002, China \\ ${ }^{2}$ College of Agronomy, Henan Agricultural University, Zhengzhou 450002, China \\ ${ }^{3}$ Hua County Agricultural Technology Popularization Center, Hua county 456400, China \\ zhanghaohnnd@126.com, xinmingma@126.com
}

\begin{abstract}
To study crop recommendation fertilization of the rural farmers as the main in our country, the paper took towns and villages of Hua County as the study area, took recommendation fertilization of wheat, maize and peanut as the study object, designed model components of crop balance fertilization by using Object-Oriented technique, and developed the decision-making system about crop recommendation fertilization based on ArcGIS Server at village scale. The decision-making system realized farmland nutrient management and fertilization recommendations decision-making according to soil output capacity, agricultural production level and crop target yield. It was successfully applied in crop production in Hua County. The research results show that the system has the characteristic of better expansibility than before, and it is significantly simple and practical to reduce crop production cost and increase agricultural production efficiency, which provides technical support for crop fertilization decision-making and is significant to improve agricultural ecological environment and increase the comprehensive production capacity of farmland.
\end{abstract}

Keywords: Nutrient balance model, Fertilization decision-making, Crop, WEBGIS, Village scale

\section{Introduction}

Soil testing and balance fertilizer is one of the important technologies of precision agriculture, and also currently the development direction of scientific fertilization in agriculture production[1-3]. Precision fertilization is the optimized combination of information technology (RS, GIS and GPS), biotechnology, chemical technology and mechanical technology, and it can be divided into basic fertilizing and aftermanuring according to crop growth period, arable farming and broadcast application according

$1 *$ Corresponding author. 
2 Hao Zhang1, Li Zhang1, Yanna Ren1, Juan Zhang1, Xin Xu1,Xinming Ma1,2*,

Zhongmin Lu3

to fertilization methods, real-time and non real-time precision fertilization according to the timeliness.

Currently, using of modern information technology to build decision-making system of precision fertilizer for changing the traditional fertilization custom is the research hotspot of precision fertilization. Many scholars has researched and developed GIS-based precision fertilizer management systems and decision-making systems mostly taking farmland as object[4-5], but ignored the status of farmers as the main farming in the village of China. The developed system has limitations of regional application, and it led to complex management, high cost, high pollution and difficult popularization. So, it is significant to realize a simple, expansible and practical system for lowering system complexity, reducing crop production cost and strengthening system pervasiveness, in order to increase agricultural production efficiency, improve agricultural ecological environment and enhance agricultural comprehensive production capacity.

With the development of modern information technology, ArcGIS Server is lowcost, complete and efficient. The paper took crop fertilization decision-making at administrative village scale as research object, collected soil information and map village-level vector by ArcView, then constructed crop recommendation fertilization decision-making system based on ArcGIS Server and implemented village-level farmland nutrient management and on-line fertilizer recommendation. It facilitated on-line soil information query and fertilization decision-making, and provided technical support for the scientific fertilization.

\section{Data Source and Research Method}

\subsection{Data Source}

Research data included meteorological data, soil data and crop data. Meteorological data was made up of daily maximum temperature, daily minimum temperature, daily average temperature, daily rainfall and daily sun actual exposure hours, provided by the Weather Bureau of Henan Province. Soil data was consist of soil type, soil nutrients and soil texture, collected from the Henan TuRang DiLi[6] or provided by the county soil and fertilization station. Crop data was consist of crop species, crop varieties, planting region, planting area, yield per hectare, the annual production and the multiple cropping index, collected from the Statistical Yearbook of Henan Province.

\subsection{Research Method}

Taking into account the decentralized status of crop fertilization management in village and the traditional hand fertilizing feature with farmers as the main farming, the paper took administrative villages in Henan Hua County as the study region, food 
Design and Implementation of Crop Recommendation Fertilization Decision System Based on

WEBGIS at Village Scale 3

crop (wheat and maize) and cash crop (peanut) decision-making fertilization as the study object, designed the components of nutrient balance model and fertilization decision-making model by using componentware technology[7-9], and implimented the system of on-line soil nutrient management and fertilization decision-making recommendation by using .NET Framework, ArcGIS Server and network database.

\subsection{Nutrient Balance Model and Fertilization Decision-Making Model}

Generally, crop fertilization models included ASI nutrient grading model[10-11], nutrient balance model[12] and subtraction method of soil fertility [13]. In view of the status of farmer as the main farming in China, decentralized farmland division, diverse soil type and different soil fertility, so, it was very difficult to extract all plots' nutrients accurately. The paper extracted soil nutrient information of the representative point at all directions in the villages, and gave fertilization scheme by using nutrient balance model and fertilization decision-making model. The given fertilization scheme included crop target output, fertilizer recommendations and fertilization technologies recommendations. Fertilizer recommendations included fertilizer selection and main nutrient content conversion of organic fertilizer. Fertilization technologies recommendations included when and how to fertilize. In practice, in order to apply fertilizer expediently, the paper only considered $\mathrm{N}, \mathrm{P}$ and K[14]. Formula 1 shows the balance fertilization model:

$$
M=(U * T-S) / P / C
$$

In formula (1): $M$ is fertilization weight per hectare. $U$ is crop absorbable nutrient weight from soil pre $100 \mathrm{~kg}$, which is queried from table of crop absorbable nutrient. $T$ is crop target output, which is divided into 3 grades according to the soil output capability. Table 1 shows the target output of wheat, maize and peanut in Hua county. $S$ is soil nutrient supply, which equals to tested soil nutrient value multiplied by 0.15 and effective coefficient of soil nutrient. Table 2 shows the effective coefficient of soil nutrient about wheat, maize and peanut in Hua county. $P$ is crop fertilizer absorptivity in planting season, which is queried from fertilizer classification table, shown by Table 3 . $C$ is fertilizer nutrient content, which is also queried from fertilizer classification table.

Table 1. Crop target output( $\left.\mathrm{kg} \cdot \mathrm{hm}^{-2}\right)$

\begin{tabular}{clcc}
\hline Crop type & $\begin{array}{c}\text { High target } \\
\text { output }\end{array}$ & $\begin{array}{c}\text { Middle target } \\
\text { output }\end{array}$ & $\begin{array}{c}\text { Low target } \\
\text { output }\end{array}$ \\
\hline Wheat & $9000 \sim 9750$ & $8250 \sim 9000$ & $6750 \sim 8250$ \\
Maize & $9750 \sim 11250$ & $8250 \sim 9750$ & $6750 \sim 8250$ \\
Peanut & $7500 \sim 9000$ & $6000 \sim 7500$ & $4500 \sim 6000$ \\
\hline
\end{tabular}

Table 2. Effective coefficient of soil nutrient

\begin{tabular}{cccc}
\hline Crop type & $\mathrm{N}$ & $\mathrm{P}$ & $\mathrm{K}$ \\
\hline Wheat & $0.30 \sim 0.60$ & $0.40 \sim 0.60$ & $0.30 \sim 0.80$ \\
Maize & $0.20 \sim 0.60$ & $0.50 \sim 0.60$ & $0.40 \sim 0.80$ \\
Peanut & $0.20 \sim 0.55$ & $0.50 \sim 0.60$ & $0.30 \sim 0.70$ \\
\hline
\end{tabular}


4 Hao Zhang1, Li Zhang1, Yanna Ren1, Juan Zhang1, Xin Xu1,Xinming Ma1,2*, Zhongmin Lu3

Table 3. Crop fertilizer absorptivity in planting season

\begin{tabular}{cccc}
\hline Crop type & $\mathrm{N}$ & $\mathrm{P}$ & $\mathrm{K}$ \\
\hline Wheat & $0.30 \sim 0.45$ & $0.15 \sim 0.25$ & $0.15 \sim 0.40$ \\
Maize & $0.20 \sim 0.40$ & $0.10 \sim 0.25$ & $0.05 \sim 0.40$ \\
Peanut & $0.40 \sim 0.45$ & $0.15 \sim 0.25$ & $0.45 \sim 0.60$ \\
\hline
\end{tabular}

\section{System Design}

\subsection{System Architecture}

System adopted three-tier structure: Brower/ ArcGIS Server/DBMS(application layer, logic components layer and data layer). Fig.1 shows the system architecture.

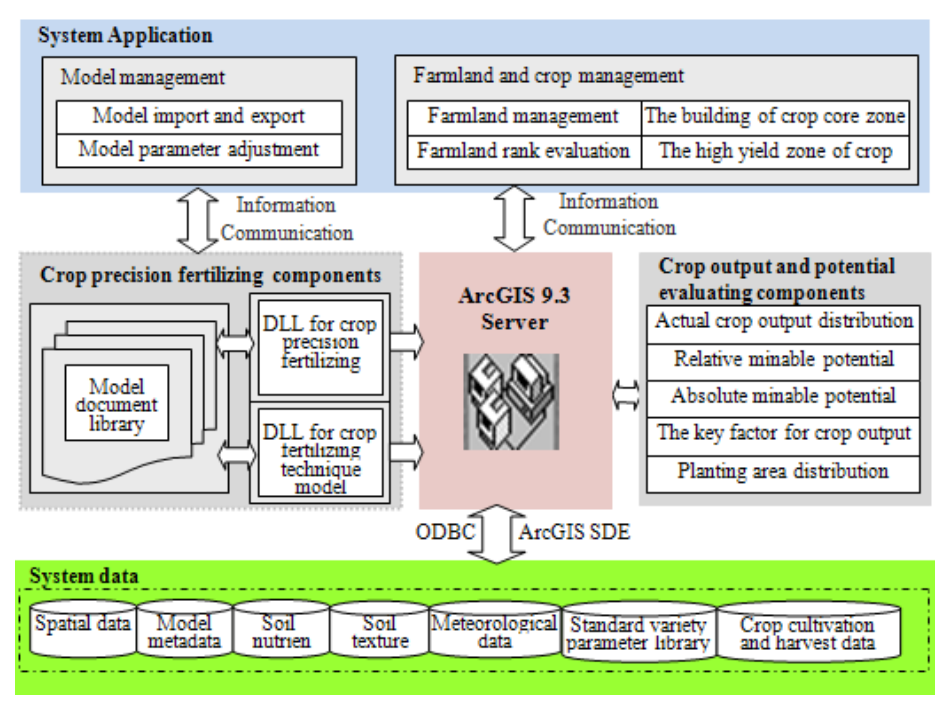

Fig. 1. System architecture

Data layer provides data service for logic components layer. The logic components layer is based on data layer and provides logic service for system application layer. It is consist of the balance fertilization model component and precise fertilization technology model component, designed and implemented by using $\mathrm{C}$ \# and relatively independent from each other. Application layer is based on logic components layer and made up of the module of model management and the module of farmland and crop management. Model management function includes importing and exporting models, rule revise and parameter adjustment. Farmland and crop management function includes farmland information management, cultivated land fertility evaluation, crop high yield region and grain core region construction. Based on the 
Design and Implementation of Crop Recommendation Fertilization Decision System Based on WEBGIS at Village Scale 5

unified database interface, data storage and operation are done through MS SQL Server 2005 and Arc SDE. The components of balance fertilization model and precise fertilization technology model are designed and implemented by using $\mathrm{C} \#$ and are loosely integrated with ArcGIS 9.3 platform, where various thematic analysis and release are realized by using ASP.NET and ArcGIS Server.

\subsection{System Function Structure}

System function included data management, information statistic and summary, balance fertilization model management, fertilization recommendation and print, special topic analysis and release, user roles management and systems help. Fig. 2 shows the system function structure.

Data Management. It included spatial and attribute data. Spatial data was made up of all types of point, line and plane vectorgraph. Attribute data was made up of meteorological data, soil data and crop data.

Information Statistic and Summary. It included vectorgraph and attribute query, statistic and summary for all kinds of information.

Crop Fertilization Model Management. Crop fertilization models included crop nutrient balance model and fertilization decision-making model. The management function was made up of model import and export, rule revise and parameter adjustment.

Fertilization Recommendation and Print. According to monitoring point nutrient information and crop output target, system gave and printed the unit fertilization weight and recommendation technology.

Special Topic Analysis and Release. It included the topic analysis and release of microelement $(\mathrm{Cu}, \mathrm{Ca}, \mathrm{Mn})$, macroelement $(\mathrm{N}, \mathrm{P}, \mathrm{K})$ and organic matter.

User Rights Management. It distributed authority of user role and added, deleted, updated, and queried user information.

\subsection{Database Design}

System database structure was made up of spatial database, attribute database, model library and knowledge library, shown in Fig. 3(a). Spatial database was built by using ArcView in scale of 1:20,000, and was consist of town point and line vectorgraph, administrative village point and line vectorgraph and soil monitoring point vectorgraph, shown in Fig. 3(b). 
6 Hao Zhang1, Li Zhang1, Yanna Ren1, Juan Zhang1, Xin Xu1,Xinming Ma1,2*, Zhongmin Lu3

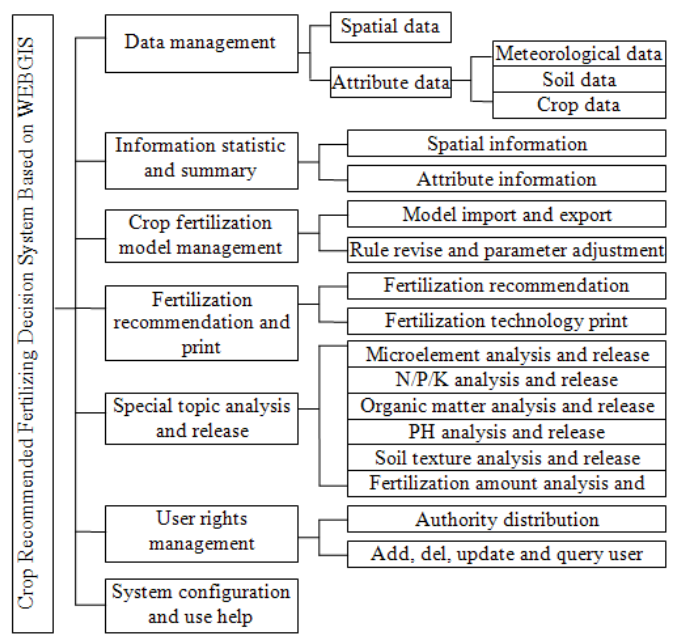

Fig. 2. System function structure

Attribute database was built by using E-R model, and was consist of administrative division data, farmland data, soil monitoring point data and crop cultivation and harvest data. Administrative division was made up of towns and administrative villages. Farmland data included the latitude and longitude, area, soil type, soil productivity level, their villages and their farmers. Soil monitoring point data was made up of soil texture, total nitrogen, alkali-hydro nitrogen, $\mathrm{P}_{2} \mathrm{O}_{5}, \mathrm{~K}$, Organic matter, $\mathrm{pH}$, and so on. Crop cultivation and harvest data included crop type, crop variety, crop planting acreage, crop yield and multiple index. Fig. 3(c) shows attribute database.

Model library was made up of the decision-making field ID, model ID, model type, model name, model application conditions, model premise items, units, data type, data length, decimal digits and credibility. Knowledge library was made up of expert fertilization scheme, fertilizer type selection, main nutrient content conversion of organic fertilizer and fertilization technique recommendation.
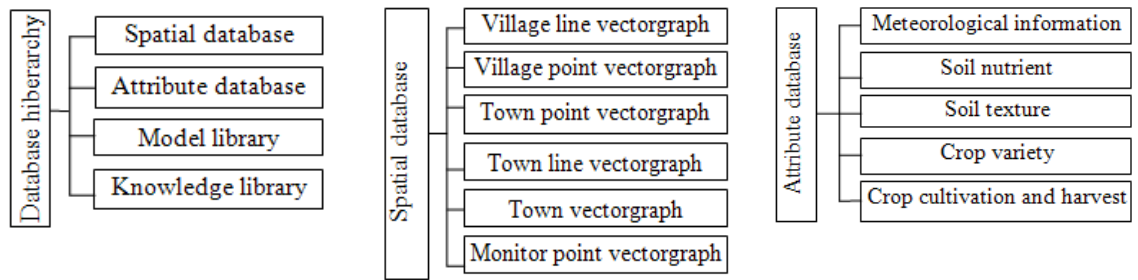

Fig. 3. System database design

(a)System database structure (b)Spatial database (c)Attributte database 
Design and Implementation of Crop Recommendation Fertilization Decision System Based on WEBGIS at Village Scale 7

\section{System Implementation and Application}

Taking crop production in Hua county as an example, the paper collected nutrient information of 3,773 soil monitoring points at all orientations of 976 administrative villages in 22 towns, and built soil fertility database. The nutrient balance model component and fertilization decision-making model component were designed by using OO and UML2.0, and WEBGIS-based fertilization decision-making system was implemented by using C \#, ASP.NET, ArcGIS Server and MS SQL Server 2005.

System may be installed in Win2000/2003/XP on PC or touch screen system. First, farmer may select and query the fertility information of soil monitoring point at 4 orientations of each administrative village, shown in Fig. 4. Second, system buffered and analyzed the selected point, and the nearest soil monitoring point close to the selected point from the buffer was chosen. Third, crop target output was selected according to the level of local production. Finally, the system gave formula fertilization weight decision and fertilization technology decision according to soil monitoring point information, crop target output and local production level, shown in Fig. 5.

\section{Conclusion}

System is developed by following OOAD standard and farmland nutrient balance components and fertilization decision-making model components are customized by using componentware technology. The system has the characteristics of modularization, encapsulation, reusability and inheritance. It can be installed in Win $2000 / 2003$, and is easy and convenient for farmers to query farmland nutrient information and on-line fertilization recommendation at village scale through network. The system has been applied in Hua county agriculture production and it is popular with farmers. The results show that it lowers the complexity of system management by using componentware technology, and reduces crop production cost and strengthens system pervasiveness by using WEBGIS and crop nutrient balance model and fertilization decision-making model.

According to the actual situation of soil fertility distribution, soil type and fertility are different in the same direction. So, it is deficient that one selected soil monitoring point represents all small-scale plots' fertility, even selecting one sampling point in hundreds of acres of the same direction. So, further issue is the selection of soil fertility points at a smaller scale and the analysis of soil nutrient variability.

Acknowledgments. This work is supported by "Eleventh Five-Year" national scientific and technological support and major project plan: "High-yield Crop Science and Technology Engineering"(2006BAD02A07-4), specific industry research sponsored by ministry of agriculture(20083028) and "863" plan(2006AA10Z271). Sincerely thanks are also due to the Hua County Agricultural Technology Popularization Center for providing the data for the work. 
8 Hao Zhang1, Li Zhang1, Yanna Ren1, Juan Zhang1, Xin Xu1,Xinming Ma1,2*, Zhongmin Lu3

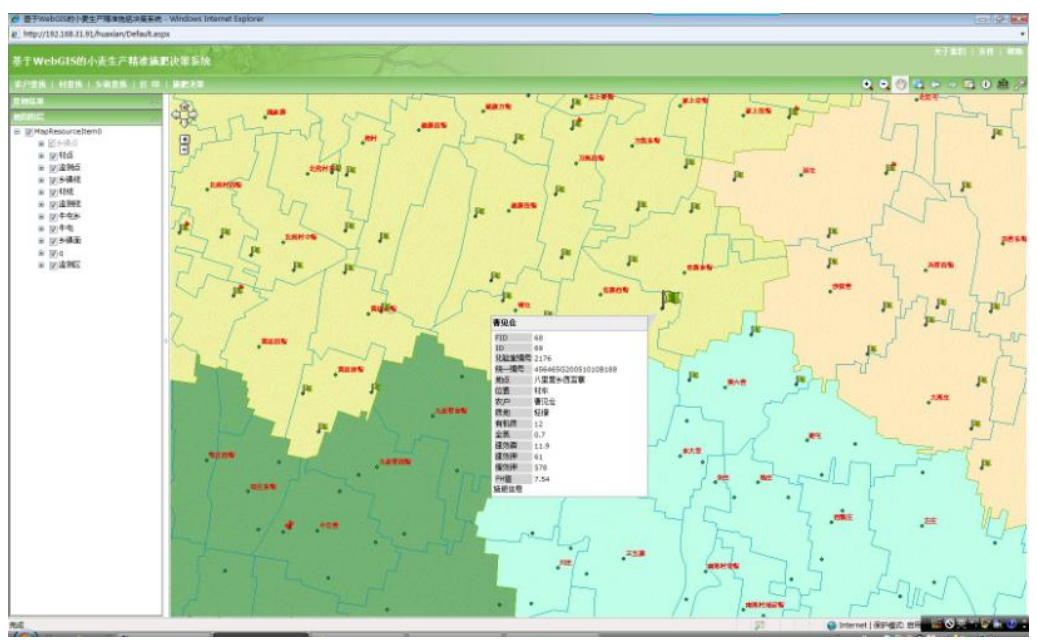

Fig. 4. The fertility information interface of crop monitoring points

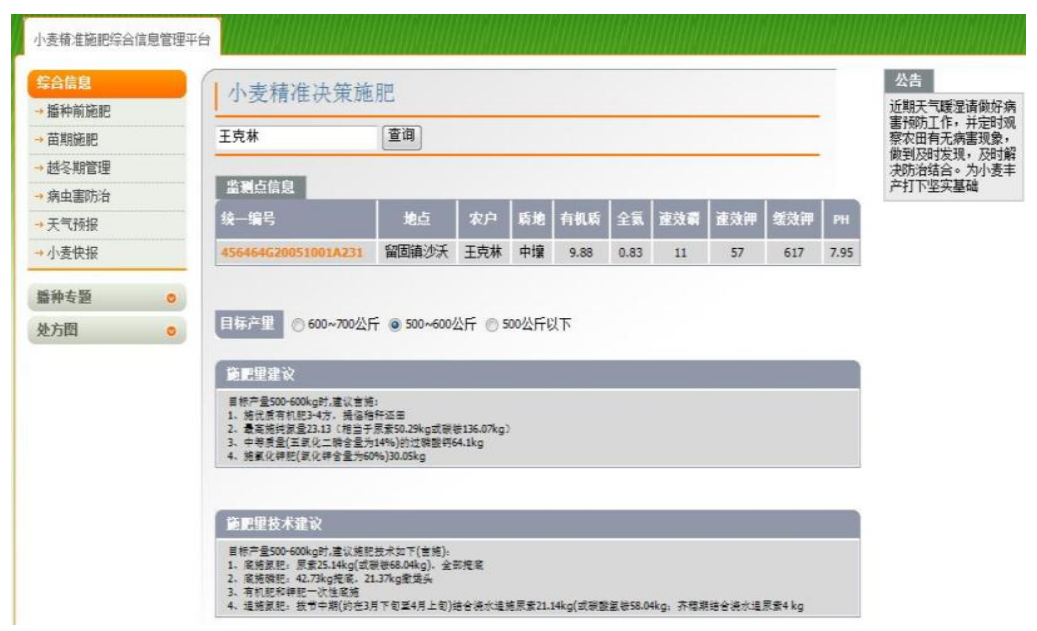

Fig. 5. Decision-making fertilization interface

\section{References}

1. Wang, M. H.: Farmers Need Real Information. IChina. 13, 19 (2006)

2. Zhang, H., Li, F.C., Ma, X.M., Gao, R., Xia, B., Lu, Z.M.: Design and Realization of GISBased County Testing Soil for Wheat Formulated Fertilization System. Jour. Hen. Agri. Uni. 5, 566--569(2008) 
Design and Implementation of Crop Recommendation Fertilization Decision System Based on WEBGIS at Village Scale 9

3. Zhang, H., Xi, L., Yu, H., Xiong, S.P., Qiao, H.B., Lu, Z.M. and Ma, X.M.: Design Of Decision-making System about Wheat Survey and Directions for Soil Based on GIS in County. In: 3th Computer and Computing Technologies in Agriculture, pp. 661-670. Springer Press, New York (2009)

4. Sheng, J.D., Li, R.: An Information System of Soil Nutrition Management and Crop Fertilizer Recommendation Based on GIS. Soils. 2, 77--81, 112 (2002)

5. He, L.Y., Miao, J.: Research of Farmland Resource Management and Application Model Based on Web GIS. In: 3th Computer and Computing Technologies in Agriculture, pp. 8-14. China Agricultural Science and Technology Press, Bei Jing(2007)

6. Wei, K.X.: Henan TuRang Dili.: Henan Science and Technology Press, He Nan(1995)

7. Zhao, C.J., Wu, H.R., Yang, B.Z., Sun, X., Wang, J.H., Gu, J.Q.: Development Platform for Agricultural Intelligent System Based on Techno-Componentware Model. Trans. CSAE. 2, 140--143(2004)

8. Xi, L., Ma, X.M., Li, F.C., Liu, H.B., Ren, Y.N., Li, Y.H.: Design and Implementation of Crop Growth Simulation System Based on Techno-Componentware Model. Jour. Hen. Agri. Uni. 3, 317--320(2005)

9. Zhang, H.: Research of Crop Production Potential System Based on OMT and Software Component Technique. The PLA Information Engineering University, Zheng Zhou(2009)

10.Yang, L.P., Jin, J.Y.: Study on the Correlation between ASI and Routine Method to Determine Soil Available $\mathrm{P}, \mathrm{K}, \mathrm{Zn}, \mathrm{Cu}, \mathrm{Mn}$ and the Conventional Chemical Methods. Chinese Jour. Soil. Scie. 6, 277--279(2000)

11.Xiong, G.Y., Liu, D.B., Chen, F.: Study on the Correlation between ASI and Routine Method to Determine Soil Available P and K and Ammonium Nitrogen. Soil. Fert. 3, 73-76(2007)

12.Wang, H.T., Bai, D.P., Chen, M.C.: A Systematic Study on Nutrient Status and Its Application in Balanced Fertilization. Jour. Shan. Agri. Scie. 4, 31--36(2001)

13.Zhou, S.Z., Dai, Y., Yao, M.Y.: Application of Dissimilar Subtraction Method of Soil Fertility in Recommend Fertilizer Practice for Maize Planting in Yellow Clay Soil. Gui. Agri. Scie. 6, 34--36(2003)

14.Xie, G.D., Chen, S.H.: Spatial Continuous Variation of Environment and Precision Agriculture, pp. 18--19. Meteorological Press, Bei Jing(2005) 